\title{
Development of a National Genetic Evaluation for Cow Fertility
}

\author{
P. M. VanRaden, A. H. Sanders, M. E. Tooker, R. H. Miller, \\ H. D. Norman, M. T. Kuhn, and G. R. Wiggans \\ Animal Improvement Programs Laboratory, Agricultural Research Service, \\ USDA, Beltsville, MD 20705-2350
}

\begin{abstract}
A national fertility evaluation was developed based on pregnancy rate, which measures the percentage of nonpregnant cows becoming pregnant within each 21$\mathrm{d}$ opportunity period. Data for evaluation are days open, which are calculated as date pregnant minus previous calving date. Date pregnant is determined from last reported breeding or from subsequent calving minus expected gestation length. Success or failure of last breeding can be confirmed by veterinary diagnosis or a report that the cow was sold because of infertility. Data are adjusted for parity and calving season within geographic region and time period and evaluated. Fertility records are considered complete at $250 \mathrm{~d}$ in milk, and lower and upper limits of 50 and $250 \mathrm{~d}$ are applied to days open. For calculation of genetic evaluations, days open are converted to pregnancy rate by the linear formula pregnancy rate $=0.25$ (233- days open). Evaluations are expressed as predicted transmitting ability for daughter pregnancy rate, and calculation is done with an animal model. Genetic correlations among several fertility measures and other evaluated traits were estimated from 3 large data sets. Correlation with days open was less for nonreturn rate than for days to first breeding, probably because nonreturn rate had lower heritability. Cow fertility was negatively correlated with yield but is a major component of longevity. Thus, recent selection for longevity may have slowed the longterm decline in fertility. Direct selection for fertility could halt or reverse the decline.
\end{abstract}

(Key words: fertility, genetics)

Abbreviation key: AIPL = Animal Improvement Programs Laboratory, DPR = daughter pregnancy rate, $\mathbf{P L}=$ productive life .

\section{INTRODUCTION}

Cow fertility data such as calving interval and days open have been available from DHIA for many years,

Received November 18, 2003.

Accepted January 20, 2004.

Corresponding author: P. M. VanRaden: e-mail: paul@aipl. arsusda.gov. but were not evaluated routinely because fertility traits tend to have low heritability ( 0.04). Unfavorable genetic correlations between yield and fertility are well known (Dematawewa and Berger, 1998). Freeman (1986) predicted that "continued successful selection for production may depress reproduction to where selection on reproduction may be necessary" and raised the question "...will reproductive physiologists develop new techniques to enhance reproductive performance so that selection will not be necessary?" New reproductive management tools such as estrus synchronization have been developed, but genetic selection is needed because cow fertility continues to decline (Lucy, 2001).

At least 13 other countries already evaluate cow fertility traits. Documentation of the data, methods, and genetic parameters used in most of these national evaluations, including reference to original research publications, is available from Interbull (2003). Several countries including Germany, France, Israel, Norway, and the Czech Republic evaluate only first-insemination conception or nonreturn rate, traits that have very low heritability (0.01 to 0.03). Two countries evaluate whether the cow was inseminated (New Zealand) or became pregnant (Australia) early in lactation as binary traits. Several countries measure interval traits such as days to first breeding or days open, which tend to have higher heritability (0.04 to 0.06 ), but lactation records may take longer to obtain. The Netherlands, Denmark, Sweden, and Switzerland evaluate more than one fertility trait and, until recently, had more detailed recording systems than that of the United States. Several countries measure overall reproductive success, which includes variation caused by ability to cycle, ability to conceive, and other factors such as embryo loss.

Fertility trait definitions differ greatly across countries. Only Ireland adjusts fertility evaluations for correlations with yield traits, which is surprising given that most countries adjust their longevity evaluations for correlations with yield. A few countries evaluate heifer fertility as a separate trait. Several countries solve for bull and cow fertility effects, which are nearly uncorrelated, together in the same model. 
The purpose of this paper is to examine several measures of reproductive success and introduce a US national genetic evaluation for cow fertility.

\section{METHODS}

\section{Data}

Research was conducted using data from 2 sources. One was the national database stored at the Animal Improvement Programs Laboratory (AIPL), USDA, which includes calving interval, last insemination date, pregnancy verification (for calvings since July 2002), and disposal code (sold for infertility). The other source, which includes data for all inseminations, was the database used routinely by Clay and McDaniel (2001) to evaluate bull fertility. A national database to store all inseminations and other reproductive events was developed during 2003 but was not used in this report. The new database should allow more precise modeling of fertility in the future.

\section{Variance Estimation}

Genetic parameters were estimated using a sire model and multitrait REML with 3 data sets. The first included calving interval from first to second lactation for 1,062,791 Holsteins born from 1992 through 1994. Thus, complete productive life (PL) records were available. Cows culled for reasons other than reproductive failure before a second calving were assigned the mean calving interval of $415 \mathrm{~d}$. Those culled for reproductive failure were assigned the trait limit for calving interval of $530 \mathrm{~d}$. Records of the culled cows were necessary to analyze longevity, but the standard deviation of calving interval may have been reduced by the constant values assigned. The analysis also included standardized first lactation yields and SCS from the AIPL database.

Two sets of more recent data were 2,195,643 Holstein and 145,976 Jersey lactation records initiated from 1998 through 2000 . These data sets included all insemination data, which were used to calculate days to first breeding, days to last breeding, number of services, and 70-d nonreturn rate. Gestation length was also calculated for a subset of 1,206,072 Holsteins that had a date of next calving. Correlations of gestation length with official service sire and daughter calving difficulty evaluations (Van Tassell et al., 2003) were also obtained.

\section{Pregnancy Rate}

Pregnancy rate measures how quickly cows become pregnant again after calving. It is defined as the percentage of nonpregnant cows that become pregnant dur-

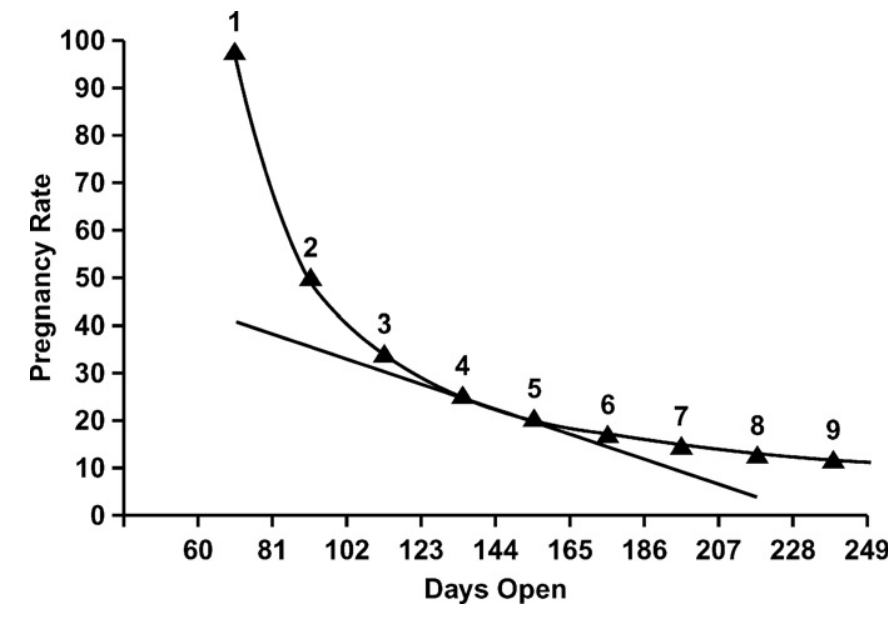

Figure 1. Comparing nonlinear and linear formulas to convert from days open to pregnancy rate when a cow has one chance (numbered) to become pregnant during each 21-d cycle.

ing each 21-d period, because each estrus cycle represents one chance for a cow to become pregnant. In recent years, many reproductive specialists have recommended this measure of reproductive success over the more traditional measure days open: pregnancy rate calculations are more current; cows that do not become pregnant are included in calculations more easily; and larger rather than smaller values are desirable, simplifying selection by producers.

$$
\begin{aligned}
& \text { Pregnancy rate }=21 /(\text { days open } \\
& - \text { voluntary waiting period }+11),
\end{aligned}
$$

where voluntary waiting period is the initial phase of lactation during which no inseminations occur. The voluntary waiting period may vary across herds or seasons but would not affect genetic evaluations unless it differed for cows within the same herd-year-season. The constant factor of 11 centers the measure of possible conception within each 21-d time period such that cows conceiving during the first 21-d period receive $100 \%$ credit on average and so on. As an example (assuming a voluntary waiting period of $60 \mathrm{~d}$ ), a herd that averages $154 \mathrm{~d}$ open has a pregnancy rate of $20 \%$ while a herd averaging 133 days open has a pregnancy rate of $25 \%$.

Across the possible range of days open, this formula produces far from linear results (Figure 1). However, across the smaller range of daughter means that result from sire genetic differences, the curve can be well approximated by a straight line. Both days open and pregnancy rate have low heritability (about 0.04 ), and the genetic components are nearly linear functions of each other. Each increase of $1 \%$ in PTA pregnancy rate 
equals a decrease of $4 \mathrm{~d}$ in PTA days open. The genetic correlation between days open and pregnancy rate is extremely high (0.99) because the only way to reduce days open is for cows to become pregnant at a faster rate.

Pregnancy rate could be analyzed using a separate binary (yes or no) variable within each 21 -d cycle. Cows that require more than one cycle to become pregnant would then have multiple observations per lactation, and the resulting distribution would be similar to coin tosses that are repeated until heads are observed. Using simulated data, VanRaden (2003) found little increase in accuracy of PTA by evaluating multiple observations because the heritability per observation was much lower. Thus, the simpler analysis of a single fertility record per lactation was chosen for routine evaluation.

Daughter pregnancy rate (DPR) is the fertility trait defined for routine genetic evaluation by AIPL. Records are days open data that are transformed to pregnancy rate using the simple linear function

$$
\text { pregnancy rate }=0.25 \times(233-\text { days open }) \text {. }
$$

Genetic evaluations are expressed as deviations from a base pregnancy rate within each breed. Mean DPR from AIPL is higher than corresponding pregnancy rates reported through DHIA because the latter include non-pregnant cows after 250 DIM in calculations.

\section{Routine Evaluation}

National DPR evaluations include data from over 16 million cows for over 40 million calvings since 1960 . Evaluations include up to 5 lactations for each cow (the same number as for yield traits). Date pregnant is determined from several information sources. The best information is a reported date of last insemination verified by the next calving occurring within $15 \mathrm{~d}$ of the expected date. The expected calving date is calculated by adding a mean gestation length to the date of last insemination. Gestation length was assumed to be 280 $\mathrm{d}$ for Ayrshires, Guernseys, Holsteins, Jerseys, and Milking Shorthorns vs. $290 \mathrm{~d}$ for Brown Swiss and was not adjusted for such factors as sex of calf, sire of calf, or age of cow. Genetic differences for gestation length were estimated and were small because the phenotypic standard deviation is small (Shook et al., 2002).

If the date of next freshening is not available (because the cow has been sold, the herd stopped testing, or the current date is less than the last breeding date plus the average gestation length) or is identified as an abortion, the reported date of last insemination is assumed to be the date pregnant. The last reported insemination is assumed to have failed if no calving is reported within

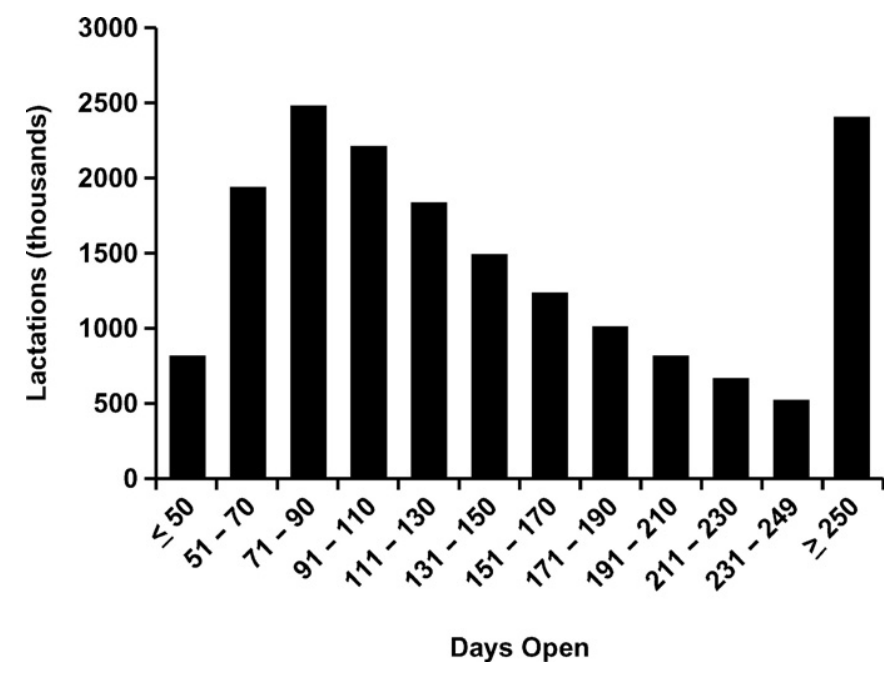

Figure 2. Distribution of adjusted days open for Holsteins calving from 1990 to 2001.

$295 \mathrm{~d}$ (305 d for Brown Swiss) and the cow is known to be still alive at that time (through continued reporting). If no inseminations are reported through DHI records, or the next calving differs from the expected calving date by more than $15 \mathrm{~d}$, the date pregnant is calculated by subtracting the mean gestation length for the breed from the date of next calving.

A final source of information for some lactations occurs when the owner reports that a cow was sold for beef because of reproductive problems. Such cows are assumed to be nonpregnant when sold. Insemination data are disregarded and days open are set to the upper limit of $250 \mathrm{~d}$ open. Records for evaluating pregnancy rate are considered to be complete at 250 DIM, and cows not pregnant by 250 DIM are also assigned 250 d open. Sensitivity to the upper limit was investigated by estimating heritability for a range of values from 150 to $305 \mathrm{~d}$ open. Cows with date pregnant less than 50 DIM were assigned the lower limit of $50 \mathrm{~d}$ open to reduce the impact of any recording errors. Figure 2 shows the distribution of adjusted days open records for Holsteins calving from 1990 to 2001 for each 20-d period between 50 and 250 DIM. These upper and lower limits affect 14 and $5 \%$ of days open records, respectively, and are imposed after adjusting for season effects within regions.

Table 1 gives the distribution of sources for fertility data in the records of recent cows. Over $80 \%$ of all records included a last insemination date or indication that the cow was sold for reproductive reasons. A majority of all records included insemination dates that were validated by subsequent calving, and in only $5 \%$ of records was a reported last insemination inconsistent 
Table 1. Sources of fertility data for cows calving in 1998 and 1999 by breed.

\begin{tabular}{|c|c|c|c|c|c|c|}
\hline & Ayrshire & $\begin{array}{l}\text { Brown } \\
\text { Swiss }\end{array}$ & Guernsey & Holstein & Jersey & $\begin{array}{l}\text { Milking } \\
\text { Shorthorn }\end{array}$ \\
\hline & \multicolumn{6}{|c|}{$-(\%$ of records $)$} \\
\hline $\begin{array}{l}\text { Breeding date verified by } \\
\text { calving date }\end{array}$ & 55 & 54 & 48 & 57 & 64 & 53 \\
\hline Breeding date only & 16 & 15 & 20 & 19 & 17 & 16 \\
\hline Calving interval only & 7 & 9 & 8 & 6 & 6 & 11 \\
\hline $\begin{array}{l}\text { Breeding disagrees with } \\
\text { calving date }\end{array}$ & 6 & 8 & 8 & 5 & 5 & 8 \\
\hline Sold for reproductive problems & 6 & 5 & 5 & 5 & 3 & 4 \\
\hline No fertility information & 10 & 9 & 11 & 8 & 5 & 8 \\
\hline
\end{tabular}

with the subsequent calving date. No subsequent calving data were available to verify reported inseminations in 15 to $20 \%$ of records. Overall, less than $10 \%$ of records provided no fertility data. Among breeds, Jerseys had the lowest percentage of cows culled for reproductive reasons, which is consistent with the smaller decline in fertility experienced by Jerseys.

To avoid selection bias, only records having the opportunity to be complete (250 DIM or greater) are included for evaluation of pregnancy rate. Recently, methods for including records in progress were developed (Kuhn et al., 2004) so that pregnancy rate can be evaluated earlier in lactation. Incorporation of these methods in routine calculation of PTA DPR began in November 2003. Incomplete and unverified records then received less weight in calculating DPR evaluations. Previously, all included records received the same weight. Fertility records are included only if the cow has a usable production record.

Pregnancy verification codes (based on veterinary diagnosis of pregnancy) were first received at AIPL during 2002; thus, statistics on completeness of reporting were not yet available. If a cow is confirmed not pregnant by veterinary diagnosis, her last insemination date is ignored and her days open equals DIM. A new reproductive event format (format 5) now allows other variables to be reported, including the date of the diagnosis.

Records were adjusted for region, year of calving, and season of calving effects prior to analysis. Records were categorized in 5 U.S. geographic regions based on climate, 5 time divisions since 1960, and month of calving. Some breeds had insufficient numbers of herds to obtain accurate adjustments for all categories. Thus, based on the similarity of estimates, adjustments calculated for Jerseys were applied to Guernsey records, and adjustments calculated for Holsteins were applied to records from the other breeds.

Initial research indicated that for all breeds fertility is best following fall calvings and poorest following spring calvings (Figure 3). This was expected because fewer cows express estrus or conceive during hot summer months (De Rensis and Scaramuzzi, 2003). Season effects have increased over time such that adjustments are somewhat larger for current data and somewhat smaller for older data compared with the overall estimates in Figure 3. Reasons may be an increasing standard deviation across time and a larger effect of heat stress with higher production. Season effects were largest for Holsteins and for the Southeast region. Recent Holstein data show that spring calvings in the southeastern United States result in many more days open (Oseni et al., 2003).

Herd variance adjustments are applied to data after adjustments for season within region using the same procedures as for yield traits (Wiggans and VanRaden, 1991). Variation in days open has increased over time and is greater in herds with higher means. For yield traits, heritability is assumed to be higher in higher variance herds. For fertility, herd differences in heritability were not investigated, and thus heritability was assumed to be constant across herds. Differences in

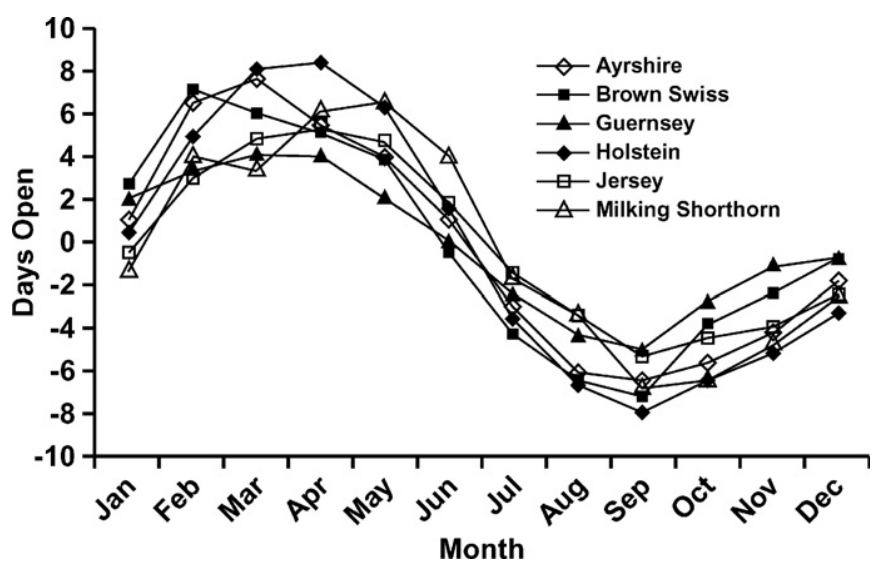

Figure 3. Mean effect of month of calving on days open by breed. 
Table 2. Genetic parameters (heritabilities on diagonal, genetic correlations above diagonal, and phenotypic correlations below diagonal) for first-lactation traits and productive life of Holsteins.

\begin{tabular}{lcccccr}
\hline & Days open & Productive life & Milk & Fat & Protein & SCS \\
\hline Days open & 0.037 & -0.59 & 0.38 & 0.33 & 0.32 & 0.30 \\
Productive life & -0.20 & 0.076 & 0.03 & 0.04 & 0.06 & -0.31 \\
Milk & 0.11 & 0.13 & 0.264 & 0.44 & 0.81 & 0.25 \\
Fat & 0.09 & 0.11 & 0.69 & 0.226 & 0.58 & 0.14 \\
Protein & 0.10 & 0.14 & 0.90 & 0.75 & 0.224 & 0.26 \\
SCS & 0.05 & -0.13 & -0.09 & -0.09 & -0.06 & 0.108 \\
\hline
\end{tabular}

PTA calculated with and without the variance adjustments were small.

Cow fertility records are processed with the same animal model programs AIPL uses for yield traits, PL, and SCS. Cows in the same herd and management group are compared directly, and the definition of management group is the same as for yield traits except when cows change herds during a lactation. For yield traits, the herd providing the most information is the herd of evaluation. For pregnancy rate, the herd in which the cow became pregnant (based on the next test date after date pregnant) or was sold for reproductive reasons is the herd of evaluation. Open cows are evaluated in the last reporting herd.

Fertility records are not adjusted for yield, following the practice established for PL. The animal model for calculation of PTA DPR includes adjustments for parity defined within 3 US geographic regions and 9 time periods. Records are not adjusted for age within parity because an older age at a given parity is the result of longer days open in the past and adjustment would remove part of the genetic effect.

Repeatability of days open was estimated from two subsets of the data used for routine DPR evaluations. Holstein cows sired by bulls with at least 50 daughters that first calved during the years 1996 to 1998 were included from 2 random samples of herds. The first sample included 1,198,846 records of 513,261 cows and was evaluated by a sire model including only sire relationships. The second sample included 137,922 records of 81,265 cows and was evaluated by an animal model with complete relationships. For repeatability estimation, variances were obtained with MTDFREML (Boldman et al., 1995).

\section{RESULTS AND DISCUSSION}

Based on the historical data (Holsteins born from 1992 through 1994), the heritability of days open in first lactation, calculated by calving interval, was 0.037 . Genetic correlations with first lactation milk, fat, and protein were $0.38,0.33$, and 0.32 , respectively, indicating that selection for yield reduces fertility. Genetic correlation with PL was -0.59 , indicating that cow fertility plays a major role in longevity. Table 2 provides genetic and phenotypic correlations and heritabilities for yield traits, days open, and productive life. Yield traits had lower heritabilities than official estimates (0.30). Genetic correlations of yield with PL are much lower than in the past (Powell and VanRaden, 2003), perhaps indicating increased fertility and health problems.

In the more recent data, heritability of days to last breeding (analogous to days open) was $0.04( \pm 0.002)$ for Holsteins and $0.029( \pm 0.008)$ for Jerseys. Correlations, means, standard deviations and heritabilities for traits of Holsteins are provided in Table 3. Based on the data, including all insemination dates, heritabilities for cow fertility traits in Holsteins were $0.066( \pm 0.003)$ for days to first breeding, $0.040( \pm 0.002)$ for days to last breeding, $0.018( \pm 0.001)$ for number of inseminations, 0.010 $( \pm 0.001)$ for $70-d$ nonreturn rate, and $0.103( \pm 0.004)$

Table 3. Genetic parameters (heritabilities on diagonal, genetic correlations above diagonal, and phenotypic correlations below diagonal), means, and SD for Holstein reproductive traits.

\begin{tabular}{llllllr}
\hline & \multicolumn{7}{c}{ Genetic parameters } \\
\cline { 2 - 5 } & $\begin{array}{l}\text { Days to } \\
\text { first } \\
\text { breeding }\end{array}$ & $\begin{array}{l}\text { Days to } \\
\text { last } \\
\text { breeding }\end{array}$ & $\begin{array}{l}\text { Insemi } \\
\text { nations }\end{array}$ & $\begin{array}{l}\text { Nonreturn } \\
\text { rate at 70 d }\end{array}$ & $\begin{array}{l}\text { Gestation } \\
\text { length }\end{array}$ & Mean \pm SD \\
\hline Days to first breeding & 0.066 & 0.85 & 0.15 & 0.24 & -0.01 & $90 \pm 35$ \\
Days to last breeding & 0.41 & 0.040 & 0.61 & -0.21 & -0.01 & $141 \pm 75$ \\
Inseminations, no. & 0.00 & 0.76 & 0.018 & -0.88 & 0.02 & $2.1 \pm 1.3$ \\
Nonreturn rate at 70 d & 0.00 & -0.32 & -0.57 & 0.010 & -0.03 & $0.55 \pm 0.48$ \\
Gestation length, d & 0.00 & -0.02 & -0.02 & 0.01 & 0.103 & $279 \pm 5$ \\
\hline
\end{tabular}


for gestation length. These heritabilities are similar to official estimates reported by several other countries (Interbull, 2003) and indicate that days to first breeding is an important component of fertility. Days to last breeding were more genetically correlated with days to first breeding (0.85) than with number of inseminations $(0.61)$ or nonreturn rate $(-0.21)$. Estimates for Jerseys were very similar except that days to first breeding had a lower heritability $(0.040 \pm 0.009)$. Estimates for days to first breeding and nonreturn rate for Holsteins agreed with those calculated from California and Minnesota herds by Weigel and Rekaya (2000).

Gestation length contributes very little to the variance of calving interval. The heritability of gestation length is more than twice that of days to last breeding, but the phenotypic standard deviation is less than onetenth as large. The genetic standard deviation for gestation length was small, just $1.6 \mathrm{~d}$, but these small differences are an important component of calving difficulty. Gestation length correlations were 0.32 with service sire calving difficulty and 0.22 with daughter calving difficulty based on 431 bulls that had greater than 500 observations for each trait.

A repeatability of 0.11 was obtained from literature estimates (Dematawewa and Berger, 1998) and was used in initial national evaluations. A repeatability of 0.13 was estimated subsequently from current national data in both sire model and animal model analyses. Heritabilities from the sire model and from the animal model were 0.050 and 0.038 , respectively. Officially, parameter estimates for all breeds were originally set to 0.04 for additive genetic effects, 0.01 for effect of interaction of sire and herd, and 0.06 for permanent environmental effects as fractions of total variance. Beginning with November 2003 evaluations, variance of the permanent environment effect was increased to 0.08 , reflecting the higher estimate of repeatability.

Heritability of days open increased steadily as the upper limit was decreased from 305 to $150 \mathrm{~d}$. Estimates were 0.030 at $305 \mathrm{~d}, 0.033$ at $250 \mathrm{~d}, 0.036$ at $200 \mathrm{~d}$, and 0.041 at $150 \mathrm{~d}$. Economic benefits of very early pregnancy are not as great as the costs of delayed pregnancy. Decreasing the upper limit would increase heritability but reduce the penalty for severe infertility. Thus, an official upper limit of $250 \mathrm{~d}$ was chosen so that severe fertility problems would be identified.

Figure 4 depicts the declining genetic trend for fertility by breed. Although the PTA means for animals of different breeds are not directly comparable, genetic trends can be compared across breeds. Milking Shorthorn, Jersey, and Ayrshire breeds had smaller losses of fertility across time, whereas Guernsey, Brown Swiss, and Holstein had larger losses. The smaller trend for Jerseys is consistent with the lower estimated

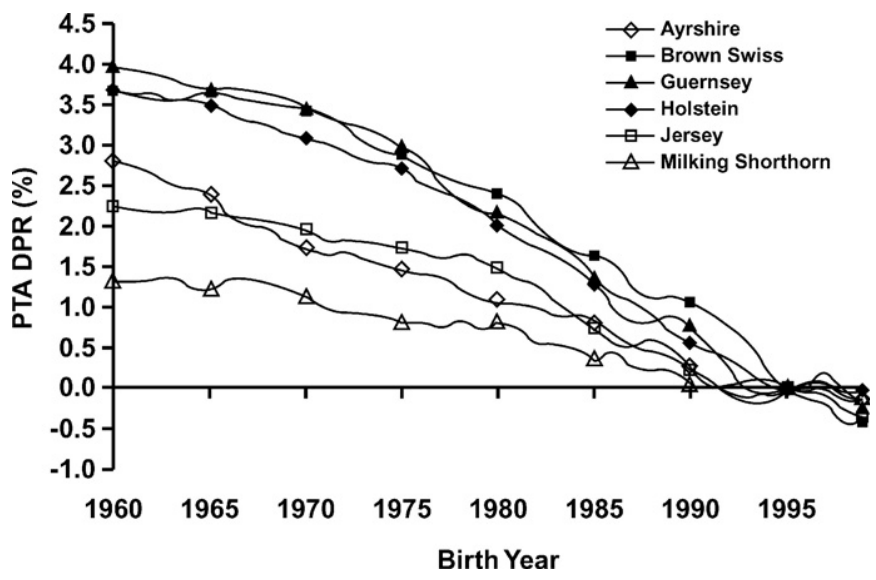

Figure 4. Trend in PTA daughter pregnancy rate (DPR) for bulls born from 1960 to 1999 by breed. The genetic bases force all lines to intersect at 0 in 1995. Trends were estimated, but breed differences were not.

heritability of days to last breeding and smaller range of PTA. The Holstein genetic trend has become nearly flat after 1994, perhaps because of selection for increased PL (introduced in 1994). The genetic trends across 4 decades are consistent with correlated responses expected from selection for high yield, but explain only about $40 \%$ of the decline in fertility shown by phenotypic trends for days open (Figure 5). These trends also indicate that yearly fluctuations in days open have an equal effect on cows for each parity. Table 4 provides statistics for bulls with active AI status in November 2002 and for cows born in 1995. The current genetic base for PTA DPR is progeny-tested bulls born in 1995. Using this bull base, DPR evaluations of currently marketed bulls are centered near zero. For recently progeny tested bulls, the correlation of PTA DPR

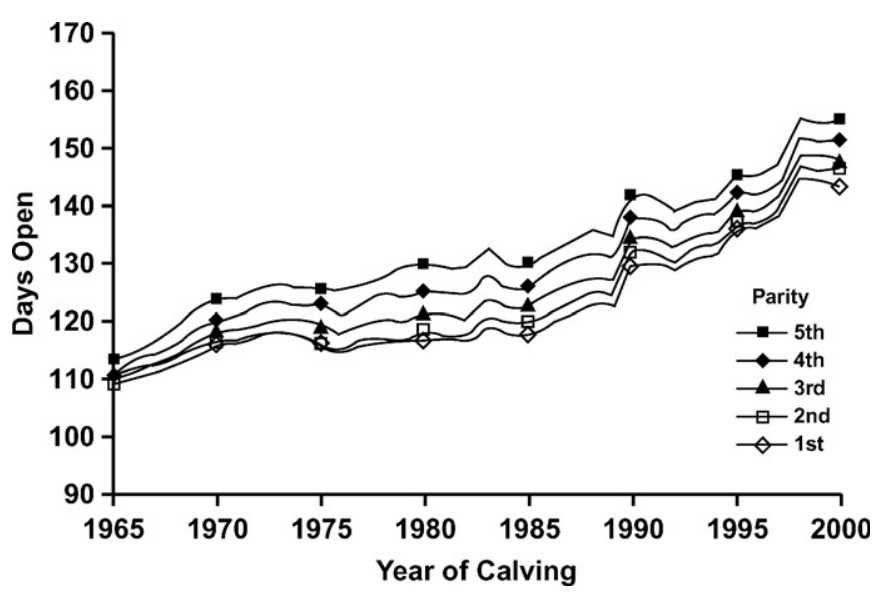

Figure 5. Phenotypic trend of days open for Holsteins by parity. 
Table 4. Daughter pregnancy rate evaluations and reliabilities (REL) for AI bulls and for cows born in 1995 by breed.

\begin{tabular}{|c|c|c|c|c|c|c|c|}
\hline & & Ayrshire & $\begin{array}{l}\text { Brown } \\
\text { Swiss }\end{array}$ & Guernsey & Holstein & Jersey & $\begin{array}{l}\text { Milking } \\
\text { Shorthorn }\end{array}$ \\
\hline & & \multicolumn{6}{|c|}{ (days) } \\
\hline $\begin{array}{l}\text { Cows born in } \\
1995\end{array}$ & Mean PTA & -0.1 & +0.6 & -0.3 & +0.4 & +0.2 & +0.5 \\
\hline \multirow{4}{*}{$\begin{array}{l}\text { Active AI } \\
\text { bulls }\end{array}$} & Mean PTA & -0.5 & +0.1 & -0.8 & -0.2 & -0.3 & +0.2 \\
\hline & Min. PTA & -2.6 & -1.9 & -2.7 & -3.3 & -2.3 & -1.4 \\
\hline & Max. PTA & +1.6 & +1.9 & +1.5 & +2.8 & +1.4 & +2.3 \\
\hline & SD PTA & 1.2 & 1.0 & 1.1 & $(\%)$ & 0.8 & 1.0 \\
\hline $\begin{array}{l}\text { Active AI } \\
\text { bulls }\end{array}$ & Mean REL & 51 & 51 & 49 & 62 & 60 & 57 \\
\hline $\begin{array}{l}\text { AI bulls born } \\
\text { in } 1995\end{array}$ & Mean REL & 47 & 50 & 48 & 62 & 58 & 52 \\
\hline $\begin{array}{l}\text { AI bulls born } \\
\text { in } 1997\end{array}$ & Mean REL & 34 & 33 & 38 & 50 & 45 & 30 \\
\hline $\begin{array}{l}\text { Cows born in } \\
1995\end{array}$ & Mean REL & 29 & 32 & 30 & 32 & 33 & 25 \\
\hline
\end{tabular}

with PTA PL was 0.46 for Holsteins but only 0.23 for Jerseys. The PTA are not as correlated as the true transmitting abilities because the phenotypic correlation is much lower than the genetic correlation for these 2 traits.

\section{CONCLUSIONS}

Several fertility traits were examined using regional and national US data. Heritabilities and correlations were consistent with literature estimates, and fertility is the largest component of PL. Fertility evaluations are based on several sources of information, including calving interval, date of last insemination, pregnancy diagnosis, and owner reports of infertility. National evaluations do not include all insemination dates because these data were not collected nationally until 2003.

Evaluations of cow fertility traits will have high reliabilities only after hundreds of daughters are recorded. For bulls with only first-crop daughters, reliabilities average about $60 \%$, and parent averages still provide much of the information. Pregnancy rate and days open are almost the same trait genetically, and a $1 \%$ increase in pregnancy rate represents a decrease of $4 \mathrm{~d}$ open.

Selection for high yield over several generations has contributed to longer calving intervals because of an unfavorable genetic correlation between yield and days open of about 0.35. Selection for PL since 1994 apparently has slowed the decline in fertility, but direct selection for fertility should be more profitable. National evaluations for cow fertility were released beginning in February 2003 and included in net merit indexes beginning in August 2003 (VanRaden and Seykora, 2003).

\section{ACKNOWLEDGMENTS}

The authors thank the many providers of DHIA fertility data included in this national evaluation, Lillian Bachellor and Leigh Walton for computational assistance, John Clay for providing individual breeding data for research, and Eileen Wall and 2 anonymous reviewers for helpful suggestions on improving the manuscript.

\section{REFERENCES}

Boldman, K. G., L. A. Kriese, L. D. Van Vleck, C. P. Van Tassell, and S. D. Kachman. 1995. A manual for use of MTDFREML. USDA, ARS, Clay Center, NE.

Clay, J. S., and B. T. McDaniel. 2001. Computing mating bull fertility from DHI nonreturn data. J. Dairy Sci. 84:1238-1245.

Dematawewa, C. M. B., and P. J. Berger. 1998. Genetic and phenotypic parameters for 305-day yield, fertility, and survival in Holsteins. J. Dairy Sci. 81:2700-2709.

De Rensis, F., and R. J. Scaramuzzi. 2003. Heat stress and seasonal effects on reproduction in the dairy cow-a review. Theriogenology 60:1139-1151.

Freeman, A. E. 1986. Genetic control of reproduction and lactation in dairy cattle. Proc. 3rd World Congr. Genet. Appl. Livest. Prod. $\mathrm{XI}: 3-13$.

Interbull. 2003. Description of national genetic evaluation systems for dairy cattle traits as practised in different Interbull member countries. http://www-interbull.slu.se/national_ges_info2/ framesida-ges.htm. Accessed Oct. 9, 2003.

Kuhn, M. T., P. M. VanRaden, and J. L. Hutchison. 2004. Use of early lactation days open records for genetic evaluation of cow fertility. J. Dairy Sci. 87:2277-2284.

Lucy, M. C. 2001. Reproductive loss in high-producing dairy cattle: Where will it end? J. Dairy Sci. 84:1277-1293.

Oseni, S., I. Misztal, S. Tsuruta, and R. Rekaya. 2003. Seasonality of days open in US Holsteins. J. Dairy Sci. 86:3718-3725.

Powell, R. L., and P. M. VanRaden. 2003. Correlation of longevity evaluations with other trait evaluations from 14 countries. Interbull Bull. 30:15-19.

Shook, G. E., K. A. Weigel, J. Sun, and J. S. Clay. 2002. Effect of data quality on genetic parameters for days to first insemination 
in dairy cattle. Proc. 7th World Congr. Genet. Appl. Livest. Prod. 29:159-162.

VanRaden, P.M. 2003. Longevity and fertility trait definitions compared in theory and simulation. Interbull Bull. 30:43-46.

VanRaden, P. M., and A. J. Seykora. 2003. Net merit as a measure of lifetime profit: 2003 revision. AIPL Res. Rep. NM\$2 (7-03), http://www.aipl.arsusda.gov/reference/nmcalc.htm. Accessed May 18, 2004.
Van Tassell, C. P., G. R. Wiggans, and I. Misztal. 2003. Implementation of a sire-maternal grandsire model for evaluation of calving ease in the United States. J. Dairy Sci. 86:3366-3373.

Weigel, K. A., and R. Rekaya. 2000. Genetic parameters for reproductive traits of Holstein cattle in California and Minnesota. J. Dairy Sci. 83:1072-1080.

Wiggans, G. R., and P. M. VanRaden. 1991. Method and effect of adjustment for heterogeneous variance. J. Dairy Sci. 74:43504357. 